\title{
Innate immune cells and their interaction with $T$ cells in hepatocellular carcinoma (Review)
}

\author{
GUO-QING HONG ${ }^{1}$, DONG CAI ${ }^{2}$, JIAN-PING GONG ${ }^{2}$ and XING LAI ${ }^{1}$ \\ ${ }^{1}$ Department of Hepatobiliary and Thyroid Breast Surgery, Tongnan District People's Hospital, \\ Chongqing 402660; ${ }^{2}$ Department of Hepatobiliary Surgery, The Second Affiliated Hospital of \\ Chongqing Medical University, Chongqing 400010, P.R. China
}

Received June 10, 2020; Accepted October 8, 2020

DOI: $10.3892 / \mathrm{ol} .2020 .12319$

\begin{abstract}
Hepatocellular carcinoma (HCC) is a malignant tumor and is associated with necroinflammation driven by various immune cells, such as dendritic cells, macrophages and natural killer cells. Innate immune cells can directly affect HCC or regulate the T-cell responses that mediate HCC. In addition, innate immune cells and T cells are not isolated, which means the interaction between them is important in the HCC microenvironment. Considering the current unsatisfactory efficacy of immunotherapy in patients with HCC, understanding the relationship between innate immune cells and $\mathrm{T}$ cells is necessary. In the present review the roles and clinical value of innate immune cells that have been widely reported to be involved in HCC, including dendritic cells, macrophages (including kupffer cells), neutrophils, eosinophils, basophils and innate lymphoid cells and the crosstalk between the innate and adaptive immune responses in the antitumor process have been discussed. The present review will facilitate researchers in understanding the importance of innate immune cells in HCC and lead to innovative immunotherapy approaches for the treatment of HCC.
\end{abstract}

\section{Contents}

1. Introduction

2. Role of innate immune cells in HCC

3. Innate immune cell regulation of the T-cell response in $\mathrm{HCC}$

4. Clinical value of innate immune cells in HCC

5. Conclusion

Correspondence to: Dr Xing Lai, Department of Hepatobiliary and Thyroid Breast Surgery, Tongnan District People's Hospital, 271 Datong, Tongnan, Chongqing 402660, P.R. China

E-mail:1x8243495@163.com

Key words: innate immune cells, T lymphocyte, immunotherapy, hepatocellular carcinoma

\section{Introduction}

Hepatocellular carcinoma (HCC) was the sixth most common cancer and fourth most common cause of cancer-related death globally in 2018 (1). The World Health Organization estimates that $>1$ million patients will die from liver cancers by 2030 (2). HCC occurs in patients with underlying liver diseases, mostly as a result of hepatitis $\mathrm{B}$ (HBV) or $\mathrm{C}$ virus infection or alcohol abuse (3). Recently, nonalcoholic fatty liver disease (NAFLD) and metabolic syndrome becoming hot topics of research as both are important risk factors for HCC (4). At present, HCC is treated mainly by resection and occasionally in combination with other therapies, including ablation, transarterial embolization and radiotherapy, transplantation and targeting therapies, however, the efficacy of treatments for patients with advanced HCC are limited (4). Immunotherapies aimed at reactivating the activity of antitumoral $\mathrm{T}$ cells have attracted wide attention in recent years (5). However, the efficacy of nivolumab (a programmed death-1 inhibitor) was unsatisfactory in patients with advanced HCC (6). This maybe in part due to the immunosuppressive microenvironment (7).

The liver is a pivotal immunological organ which serves a crucial role in host defense via numerous innate, such as dendritic cells, kupffer cells and natural killer T (NKT) cells and adaptive immune cells, such as $\mathrm{CD}^{+}$and $\mathrm{CD} 8^{+}$ T cells (8). Dysregulation of the liver's immune system leads to the occurrence of necroinflammation, which is characterized by the dysregulation of the immune regulatory network with upregulation of pro-inflammatory signals and the breakdown of immune tolerance in chronic liver disease (9). The necroinflammatory response promotes the development of HCC via the infiltration of various innate and adaptive immune cells, such as dendritic cells, natural killer (NK) cells, monocytes, neutrophils, T cells and B cells (9). It is widely accepted that the $\mathrm{T}$ cells serve important roles in the development of HCC (10). There is always a large number of exhaustive CD8 ${ }^{+}$ $\mathrm{T}$ cells in the tumor microenvironment, which makes the treatment of HCC more difficult (11). In fact, innate immune cells also contribute to tumor immunosurveillance and immune escape by assisting T cells or by secreting cytokines (9). For example, macrophages assist $\mathrm{CD}^{+}$helper $\mathrm{T}$ cells to remove senescent hepatocytes (12). Regulatory dendritic cells (DCs) produce indoleamine-2,3-dioxygenase (IDO) to promote 
tumor immune escape in HCC (13). Hence, it is important to understand the underlying interplay between immune cells and $\mathrm{HCC}$ in the tumor microenvironment. Interestingly, innate immune cells can themselves affect tumor progression, but also regulate T-cell responses to affect tumor progression (7). Considering the regulatory properties of innate immune cells, understanding the roles of innate immune cells in HCC and interaction with $\mathrm{T}$ cells in the tumor microenvironment are necessary.

In the present study several kinds of innate immune cells were reviewed that have been widely reported in HCC, including DCs, macrophages, neutrophils and innate lymphoid cells (ILCs), and the underlying mechanisms by which they regulate $\mathrm{T}$-cell responses in the occurrence and development of HCC was discussed. The present review will improve the understanding of innate immune cells in HCC and pave the way for developing new immunotherapies for patients with $\mathrm{HCC}$.

\section{Role of innate immune cells in HCC}

DCs. DCs were first discovered in 1972 (14) and are generated through bone marrow precursors and are classified into four general groups: i) Conventional DCs; ii) plasmocytoid DCs (pDC); monocyte derived DCs and Langerhans cells (15). DCs are a type of professional antigen presenting cells (APCs), which are able to activate natural killer or NKT cells and play an important role in initiating immune responses (natural killer cells and T cells) $(16,17)$.

Previous studies indicated that the absence of $\mathrm{CD} 83^{+}$ activated DCs in the liver contributed to the occurrence of HCC and the infiltration of DCs was closely associated with the prognosis of HCC $(18,19)$. In terms of mechanisms, DCs mainly activated the T-cell response to fight tumors (20). Meanwhile, IL-10 and IL-12 inhibited and enhanced DC-mediated antitumor function, respectively $(21,22)$. At present, it is widely accepted that DCs are used for improving antitumor immunity (23). However, some studies have also demonstrated that certain types of DCs have the opposite effect on HCC. For example, intratumoral pDCs were associated with poor prognosis of patients with HCC following curative resection (24). Regulatory DCs inhibited antitumor immunity by producing IL-10 and IDO and contributed to tumor immune escape via IDO in $\operatorname{HCC}(13,25)$. In addition, HCC cells in vitro led to a deterioration in biophysical properties, including osmotic fragility, cell membrane fluidity, membrane viscoelastic properties, expression of cytoskeleton protein F-actin and transendothelium migration of DCs (26). Recently, Santos et al (24) found that $\alpha$-fetoprotein (AFP) derived from HCC cells led to a deterioration in fatty acid synthesis and mitochondrial metabolism in DCs. The aforementioned findings elucidate the effect of HCC cells on DCs at the metabolic level.

Macrophages. Macrophages, which are differentiated cells of the mononuclear phagocytic lineage and are activated in response to microbe-associated molecular patterns, such as bacterial lipopolysaccharide or cytokines, such as interleukin (IL)-4, IL-5 and IL-10, have long been recognized as M1 and M2 macrophages (27,28). M1 macrophages possess proinflammatory and antitumor properties, whereas M2 macrophages possess regulatory properties for tumor growth and metastasis $(29,30)$. In addition, co-inhibitory molecules, such as B7-H3; signaling pathways, such as the Wnt/ $\beta$-catenin and STAT3 pathway and long non-coding RNAs (lncRNAs), such as cyclooxygenase 2 serve important roles in regulating the polarization of macrophages in the HCC microenvironment (31-34). The antitumoral role of M1 macrophages has been documented in HCC (28). However, a recent study found that M1 macrophages promoted the expression of programmed death ligand 1 (PD-L1) on HCC cells via IL-1 $\beta$, which supports the protumor role of M1 macrophages (35).

Tumor-associated macrophages (TAMs), mainly M2 type, can be recruited by various cytokines, such as colony stimulating factor (CFS)-1, vascular endothelial growth factor (VEGF) and chemokines (CCL2) and serve a protumor role in HCC (29). For example, TAMs can secrete IL-6 and IL-8 to promote the proliferation of HCC stem cells and epithelial-mesenchymal transition (EMT) in HCC cells $(36,37)$. In addition, NF- $\kappa$ B, STAT-3 and hypoxia inducible factor-1 (HIF-1) signaling pathways serve key roles in the interaction between TAMs and HCC cells (38). Recently, Zhang et al (36) demonstrated that TAMs promoted the metastasis and EMT of HCC cells through HIF-1 $\alpha / \mathrm{IL}-1 \beta$ signaling under a hypoxic microenvironment. Oxaliplatin has been widely used to treat patients with $\mathrm{HCC}$, and a recent study indicated that TAMs contributed to oxaliplatin resistance through autophagy in HCC (39).

On the other hand, Kupffer cells (KCs), as the sessile resident live macrophages in the liver can sense injury of the liver and activate inflammation and promote tumor growth by releasing proinflammatory or proangiogenic factors, such as IL-6, IL-1 $\beta$, VEGF and platelet-derived growth factor and recruit large numbers of inflammatory monocytes $(40,41)$. A previous study indicated that $\mathrm{KCs}$ can promote the occurrence and development of HCC by increasing the production of IL-6 in a manner dependent on the Toll-like receptor adaptor protein myeloid differentiation primary response 88 (42). Recent studies also demonstrated that $\mathrm{KCs}$ can promote the occurrence and development of HCC in the context of inflammation and fibrosis $(43,44)$. Similarly, the M1/M2 polarization of KCs regulated by lncRNA FTX can influence the progression from NAFLD to HCC (45).

In conclusion, M2 macrophages and kupffer cells promote invasion and metastasis of HCC cells and the HCC microenvironment further promotes the protumor effect of M2 macrophages and kupffer cells.

Neutrophils. Neutrophils are the first line of defense against microbial pathogens, are the predominant leukocyte subset (50-70\%) in human peripheral blood and have protumoral functions in HCC (46). Previous studies focused more on the association between neutrophil-to-lymphocyte ratio and the prognosis of HCC (47). Subsequently, Kuang et al (46) found that the accumulation of neutrophils was associated with poor prognosis in patients with HCC and promoted angiogenesis at the invading tumor edge via MMP-9. These findings were consistent with those of Li et al (48). Meanwhile, chemokines, such as chemokine (C-X-C) ligand (CXCL)1 and CXCL5 in $\mathrm{HCC}$ promote the infiltration of neutrophils and predict poor prognosis of patients with HCC $(49,50)$. As understanding 
about neutrophils has increased, the close relationship between neutrophils and HCC cells has been discovered (51). HCC cells promote the production of hepatocyte growth factor (HGF) in neutrophils via granulocyte-macrophage colony stimulating factor and in turn neutrophils promote the metastasis of hepatoma cells via the HGF/c-mesenchymal-epithelial transition factor (c-Met) axis (52). In addition, neutrophil-mediated reactive oxygen species production and telomere DNA damage contributed to the development of $\mathrm{HCC}$ and $\mathrm{NF}-\kappa \mathrm{B} 1$ weakened the protumoral effect of neutrophils in diethylnitrosamine induced murine models (53). On the other hand, neutrophils can release extensive extracellular web-like structure called neutrophil extracellular traps (NETs) that are composed of cytosolic protein, then NETs can entrap and kill bacteria and serve important roles in cancers, such as small bowel cancer, lung cancer and HCC (54). Recent studies indicated that NETs promoted the progression from nonalcoholic steatohepatitis to $\mathrm{HCC}$ and metastasis potential of HCC by promoting inflammation $(55,56)$.

Eosinophils and basophils. Eosinophils arise from multipotent $\mathrm{CD}_{3} 4^{+}$progenitor cells in the bone marrow, then develop into IL-5R $\alpha^{+}$and $(\mathrm{C}-\mathrm{C})$ chemokine-receptor $(\mathrm{CCR}) 3^{+}$mature eosinophils in a tightly regulated process directed by differential expression of several transcription factors, such as zinc finger protein, FOG family member 1, GATA binding proteins and X-box binding protein 1 (57). The number of eosinophils is increased in peripheral blood in patients with decompensated cirrhosis (58). Although eosinophils have been demonstrated to serve opposite roles in multiple tumors, such as lymphomas, breast, ovarian, uterine, bladder, lung, pancreatic, gastric, liver and colorectal tumors through secretion of growth factors, such as epidermal growth factor and transforming growth factor- $\beta 1$, promotion of angiogenesis or secretion of cytokines, such as IL-10, IL-12 (59), the exact role and underlying mechanisms of eosinophils in HCC progression remain unclear. A study indicated that eosinophils activated by IL-5 can inhibit the growth of HCC cells in vitro through direct eosinophil-mediated cytotoxicity (60). Notably, it has been demonstrated that eosinophils may serve antitumor roles in hepatobiliary cancer (61). However, the role of basophils in HCC has barely been studied.

Myeloid-derived suppressor cells. Myeloid-derived suppressor cells (MDSCs) are divided into polymorphonuclear MDSCs and monocytic MDSCs, characterized by their immunosuppressive properties, maturity status and pathology (62). The association between frequency of MDSCs and clinical prognosis in patients with HCC has been observed (63). Several studies have demonstrated that MDSCs have a protumoral effect by suppressing the functions of DCs and NK cells as well as by regulating T-cell responses in HCC (64-66). Meanwhile, $\mathrm{HCC}$ cells themselves can promote the accumulation or activation of MDSCs by hypoxia, receptor-interacting protein kinase 3 deficiency or IL-6 produced by HCC cells (67-69). In short, MDSCs serve an important role in shaping the immunosuppressive tumor microenvironment in HCC.

Innate lymphoid cells. Innate lymphoid cells (ILCs), including group 1 ILCs (ILC1s), group 2 ILCs (ILC2s) and group 3
ILCs (ILC3s) mainly reside in tissues and have similar cytokine-secreting profiles as helper $\mathrm{T}$ cell subsets in response to infections or tissue damage (70). ILCs play protumoral or antitumoral roles in immune regulation in different tumor microenvironments (71). However, the exact roles of ILCs in HCC are still unknown. A recent study found that ILCs secreted IFN- $\gamma$ to promote hepatocellular tumorigenesis in HBV transgenic mice (72). The aforementioned study suggested that the ILCs play protumoral role in HCC, however, further molecular mechanisms remain to be explored.

NK cells, which account for about a third of the lymphocytes in the liver belong to the ILC1s and are one of the main antitumor cells found in the liver (70). Functional impairment, such as decreased production of IFN- $\gamma$ from NK cells in patients with $\mathrm{HCC}$ has been observed (73). In addition, the infiltration of functional NK cells in HCC tissues can suppress disease progression and have a favorable effect on rates of overall survival and disease free survival in patients with HCC (74). It is widely accepted that the exhaustion of NK cells may contribute to the development of HCC and natural killer group 2D (NKG2D) an activatory receptor on NK cells serves a crucial role in regulating the functions of NK cells during the development of HCC (75). For instance, suppressing enhancer of zeste homolog 2 (EZH2), a transcriptional repressor of NKG2D ligands, promoted HCC cell eradication by NK cells in a NKG2D ligand-dependent manner (76). Notably, NK cell-derived IFN- $\gamma$ promotes HCC through the epithelial cell adhesion molecule-epithelial-to-mesenchymal transition (EMT) axis in hepatitis B virus transgenic (HBs-Tg) mice (77), which suggests that the roles of NK cells in the development of HCC are complicated. In addition, tumor-derived soluble MHC class I-chain related protein A (MICA), which is a ligand of NKG2D or AFP inhibit the functions of NK cells in vitro $(78,79)$. Hence, NK cells can fight against tumors, however, the tumor itself inhibits the activity of NK cells to create conditions for HCC cell growth.

In addition, NKT cells, which are closely related to NK cells, have also been implicated in HCC (80). NKT cells are characterized by the expression of surface markers of NK cells together with a single invariant $\mathrm{T}$ cell receptor in humans (81). NKT cells can directly kill tumor cells by recognizing CD1d antigen or indirectly by activating NK cells (82). Studies have demonstrated that the number of NKT cells in HCC is positively associated with rates of overall survival and recurrence-free survival, which may be related to the involvement of NKT cells in angiogenesis in the tumor microenvironment $(82,83)$. Transforming growth factor beta (TGF- $\beta$ ) derived from HCC cells is a crucial factor in the development of HCC and can inhibit the antitumoral functions of NKT cells, NK cells and T cells (84). The relationship between all of the aforementioned innate immune cells (DCs, macrophages and neutrophils) and HCC has been summarized in Fig. 1.

\section{Innate immune cell regulation of the $\mathrm{T}$-cell response in $\mathrm{HCC}$}

Regulating the $C D 8^{+} T$-cell response in $\mathrm{HCC}$. $\mathrm{CD}^{+} \mathrm{T}$ cells are the main subset of tumor-infiltrating lymphocytes that perform antitumor effector functions and serve opposing roles in promoting a chronic proinflammatory microenvironment and 


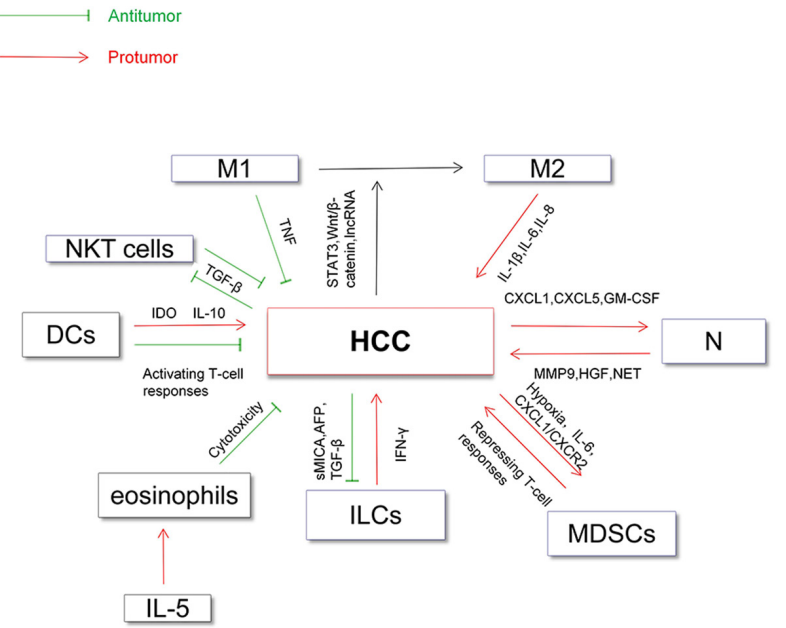

Figure 1. Direct relationship between innate immune cells and HCC. DCs may promote HCC by IDO and IL-10 and inhibit HCC by activating T-cell responses. Macrophages (M1) serve an antitumoral role and are regulated by TNF, while macrophages (M2) play a protumoral role and are regulated by IL-1 $\beta$, IL-6 and IL-8. HCC can promote M2-polarization of macrophages by signaling pathways or by lncRNA, which contributes to the immunosuppressive microenvironment. HCC cells promote accumulation of neutrophils by secretion of cytokines, such as CXCL1 and CXCL5. In turn, neutrophils promote the development of HCC by MMP9 and HGF. NET derived from neutrophils promote the metastatic potential of HCC. ILCs can secrete IFN- $\gamma$ to promote hepatocellular tumorigenesis, which may be due to the breakdown of immune tolerance. Tumor-derived soluble MICA (a ligand of NKG2D) or AFP inhibit the functions of NK cells in vitro. TGF- $\beta$ derived from HCC cells inhibit the activity of NKT cells and NK cells. MDSCs shape the immunosuppressive tumor microenvironment and HCC cells also promote the accumulation of MDSCs. DCs, dendritic cells; M1/M2, M1/M2-type macrophage; N, neutrophils; ILCs, innate lymphoid cells; IDO, indoleamine-2,3-dioxygenase; MMP9, matrix metallopeptidase 9; HGF, hepatocyte growth factor; GM-CSF, granulocyte-macrophage colony stimulating factor; NET, neutrophil extracellular traps; sMICA, soluble major histocompatibility complex class I related chains A; MDSCs, myeloid-derived suppressor cells; NKT cells, natural killer T cells; TGF- $\beta$, Transforming growth factor beta; HCC, hepatocellular carcinoma; AFP, $\alpha$-fetoprotein; lncRNA, long non-coding RNA; TNF, tumor necrosis factor; CXCL, chemokine (C-X-C) ligand motif; CXCR-2, CXC chemokine receptor 2.

in antitumor surveillance in HCC (9). For example, increasing studies indicated that the downregulation of $\mathrm{CD}^{+} \mathrm{T}$ cell function contributed to the growth of $\mathrm{HCC}$ and that strong $\mathrm{CD}^{+}$ T-cell responses may improve the prognosis of patients with HCC $(85,86)$. On the other hand, restoring the functions of $\mathrm{CD}^{+} \mathrm{T}$ cells by $\mathrm{T}$ cell immunoglobulin and immune receptor tyrosine-based inhibitory motif domain blockade or deficiency can break the adaptive immunotolerance and induce $\mathrm{HCC}$ in $\mathrm{HBsAg}-\mathrm{Tg}$ mice, which indicated the role of adaptive immunotolerance in the development of HCC (87).

In addition to adaptive immune cells, innate immune cells are also important cells for tumor surveillance (88). Meanwhile, innate and adaptive immune cells do not act independently (9). Innate immune cells can perform protumoral or antitumoral functions by regulating the $\mathrm{CD}^{+} \mathrm{T}$-cell response in HCC. For example, DCs which are professional APCs can enhance the antitumoral functions of $\mathrm{CD}^{+} \mathrm{T}$ cells by tumor-associated antigen in HCC (20). A previous study demonstrated that dendritic cell-derived exosomes (DEXs), as a cell-free vaccine, can improve the antitumor activation of $\mathrm{CD}^{+} \mathrm{T}$ cells and reshapes the tumor immune microenvironment in HCC mice (89). MDSCs can promote the exhaustion of
$\mathrm{CD}^{+} \mathrm{T}$ cells via the PD-1/PD-L1 pathway and arginase-I (62). Although the relationship between NK cells and $\mathrm{CD}^{+} \mathrm{T}$ cells has also been observed in malignant tumors (90), the molecular mechanisms and the relationship between NK cells and $\mathrm{CD}^{+}$ $\mathrm{T}$ cells remains unclear.

The roles of innate immune cells in regulating $\mathrm{CD} 8^{+} \mathrm{T}$-cell responses in HCC are complicated (23). Increasing studies suggest that innate immune cells contribute to immune escape in HCC by downregulating the $\mathrm{CD}^{+} \mathrm{T}$-cell responses (7). For example, the M2-polarization of macrophages induced by the $\mathrm{CC}$ chemokine ligand (CCL)2/C-C chemokine receptor 2 (CCR2) axis can suppress the proliferation of antitumor $\mathrm{CD}^{+} \mathrm{T}$ cells via various cytokines, such as IL-6, G-CSF and macrophage inflammatory proteins-2 (MIP-2) (91). A recent study demonstrated that natural cytotoxicity-triggering receptor-negative ILC3 could promote the growth of HCC by directly inhibiting proliferation and promoting apoptosis of $\mathrm{CD}^{+} \mathrm{T}$ cells (92). The PD-1/PD-L1 pathway has become a focus of research recently (93). Increasing studies suggest that the PD-1/PD-L1 expressed on various innate immune cells may have depressive effects on the functions of $\mathrm{CD}^{+}$ $\mathrm{T}$ cells in HCC $(35,94)$. Co-culture of T cells with macrophages stimulated by Exo-TMs (exosomes derived from tunicamycin-treated $\mathrm{HCC}$ cells) decreased $\mathrm{CD}^{+} \mathrm{T}$-cell to macrophage ratio and IL-2 production but increased T-cell apoptosis in vitro (95). The aforementioned study found that inhibition of $\mathrm{CD}^{+} \mathrm{T}$ cells was associated with upregulated expression of PD-L1 on macrophages, which contradicts the findings of Liu et al (93). In conclusion, innate immune cells can regulate the $\mathrm{CD} 8^{+} \mathrm{T}$-cell response in $\mathrm{HCC}$ by cytokines or immune checkpoints.

Regulating $\mathrm{CD}^{+}$T-cell response in $\mathrm{HCC} . \mathrm{CD}^{+} \mathrm{T}$ cells, mainly including $\mathrm{CD}^{+}$helper $\mathrm{T}$ cells (Th) and regulatory $\mathrm{T}$ cells (Tregs), also serve important roles in HCC (23). The protective function of $\mathrm{CD}^{+} \mathrm{T}$ cells in hepatocarcinogenesis has been observed in mice (96). In addition, $\mathrm{CD}^{+} \mathrm{T}$ cells promote normalized vessel formation under anti-PD-1 plus anti-VEGFR-2 therapy, leading to improvement of the hypoxic environment in HCC (97). However, Th17 cells characterized by the production of IL-17 are associated with poor prognosis in patients with HCC (98). Tregs, as immunosuppressive and antiinflammatory cells can inhibit the response of $\mathrm{T}$ cells by various cytokines, such as IL-6, IL-17 and are associated with the poor prognosis of patients with HCC (99).

Tregs play a crucial role in exhaustion of $\mathrm{T}$ cells and immune escape of HCC cells $(7,100)$. So far, increasing studies have shown the relationship between innate immune cells and Tregs, as well as underlying molecular mechanisms in HCC. For example, the increase in intratumoral pDCs was associated with increased intratumoral infiltration of forkhead box-3 (Foxp3) ${ }^{+}$regulatory T cells (24). In terms of molecular mechanisms, increased regulatory DCs induced by carcinoma-associated fibroblasts contributed to T-cell proliferation impairment and promotion of Treg expansion via IDO (13). Triggering receptor expressed on myeloid cells-1-positive tumor-associated macrophages (TREM-1+TAMs) can secrete CCL20 to promote the accumulation of CCR6 ${ }^{+}$Foxp $3^{+}$Tregs and the upregulated expression of PD-L1 in TREM- $1^{+}$TAMs contributed to depletion of $\mathrm{CD}^{+} \mathrm{T}$ cells in $\mathrm{HCC}$ both in vitro 
Table I. Clinical trials of innate immune cells based immunotherapy that have been registered in patients with HCC.

\begin{tabular}{|c|c|c|c|c|}
\hline $\begin{array}{l}\text { Type of innate } \\
\text { immune cells }\end{array}$ & $\begin{array}{l}\text { Phase of } \\
\text { clinical trial }\end{array}$ & Type of vaccine & Recruitment status & $\begin{array}{l}\text { Clinicaltrials.gov } \\
\text { identifier }\end{array}$ \\
\hline DCs & Phase I & $\mathrm{ADCC}$ and TACE & Recruiting & NCT03086564 \\
\hline DCs & Phase I & DCs vaccine and microwave ablation & Recruiting & NCT03674073 \\
\hline DCs & Phase II & $\begin{array}{l}\text { DCs vaccine and cyclophosphamide, and } \\
\text { radical surgery/TACE/targeted agents }\end{array}$ & Not yet recruiting & NCT04317248 \\
\hline NK cells & Phase I/II & Allogeneic NK cells and targeted drug & Recruiting & NCT04162158 \\
\hline NK cells & Phase II & Allogeneic NK cells after TACE & Completed & NCT02854839 \\
\hline NK cells & Phase I & $\begin{array}{l}\text { Allogeneic NK cell or/and immune } \\
\text { checkpoint inhibitors }\end{array}$ & Recruiting & NCT03841110 \\
\hline
\end{tabular}

ADCC, activated dendritic cells combined with cyclophosphamide; TACE, transcatheter arterial chemoembolization; DCs, dendritic cells; NK cells, natural killer cells.

and in vivo (101). Similarly, tumor-associated neutrophils can recruit macrophages and Tregs by the expression of CCL2 and CCL17 to promote the growth of HCC and resistance to sorafenib (102) (Fig. 2).

In addition, helper $\mathrm{T}$ cells can mediate the immune response by secreting various cytokines, such as interferon- $\gamma$, IL-4, IL-10 (103). Th1 (CXCR3 ${ }^{+}$) mainly secret interferon- $\gamma$ phenotypic, while Th2 (CRTH2 $2^{+}$) mainly secret IL-4, IL-5 and IL-13, which can resist the harm of intracellular pathogens and extracellular parasites respectively (104). Furthermore, ILC2s promoted Th2 differentiation while inhibiting Th1 differentiation in a contact-dependent manner in a co-culture system (105). Membrane-coated microvesicles derived from neutrophils suppressed a subset of Th cells by downregulating IL-2 and IL-2R expression and signaling (106). The aforementioned studies demonstrated the relationship between innate immune cells and helper T cells in a non-hepatocellular environment. However, the exact relationship and underlying molecular mechanisms between innate immune cells and helper T cells in HCC need further exploration. The roles of $\mathrm{CD}^{+}$and $\mathrm{CD}^{+} \mathrm{T}$ cells in $\mathrm{HCC}$ and their relationship with various innate immune cells have been summarized in Fig. 2.

\section{Clinical value of innate immune cells in $\mathrm{HCC}$}

Immunotherapy has been a hotspot of research since cytotoxic T lymphocyte-associated protein 4 and PD-1 inhibitors were approved to treat melanoma (51). Similarly, immunotherapy based on $\mathrm{T}$ cells has become an important therapy for patients with HCC, especially for advanced HCC, but the efficacy of treatment is still not satisfactory (107-109). Hence, a novel treatment strategy is necessary to complement immunotherapy in patients with HCC. In addition to T cells, innate immune cells which are important parts of the tumor microenvironment can also serve crucial roles and regulate T-cell responses in HCC (9). Hence, innate immune cells will be promising candidates for the treatment of patients with HCC. So far, the clinical value of DCs, macrophages and NK cells have been noticed. For example, several animal experiments have confirmed the efficacy of innate immune cells in HCC. For example, the dendritic cell-DEXs, being a cell-free vaccine can elicit

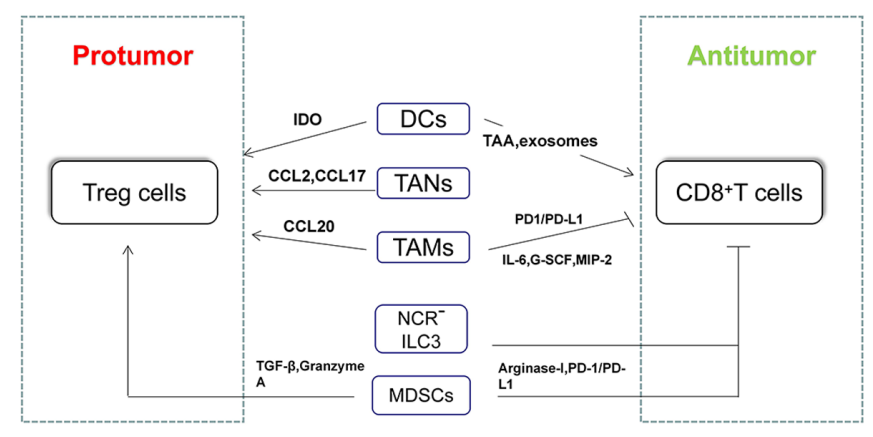

Figure 2. Main mechanisms by which innate immune cells regulate T-cell responses in HCC. CD8+ T cells and CD4+Th1 cells play antitumoral roles in HCC, whereas Treg cells and Th2 cells play protumoral roles in HCC. Innate immune cells can regulate $\mathrm{T}$-cell responses to further mediate the development of HCC. IDO, indoleamine-2,3-dioxygenase; TAA, tumor-associated antigen; MIP-2, macrophage inflammatory protein 2; G-CSF, granulocyte colony-stimulating factor; DCs, dendritic cells; TAMs, tumor-associated macrophages; TANs, tumor-associated neutrophils; NCR, natural cytotoxicity-triggering receptor; ILC, innate lymphoid cells; MDSCs, myeloid-derived suppressor cells; TGF- $\beta$, Transforming growth factor beta; HCC, hepatocellular carcinoma; PD-1, programmed death 1; PD-L1, programmed death ligand-1; Treg, T regulatory cells; CCL, CC chemokine ligand.

tumor regression in autochthonous hepatocellular carcinoma mouse models (89). Injection of M1 hydrogels (a poly ethylene glycol diacrylate and thiolated gelatin poly ethylene glycol cross-linked hydrogels capsulated with M1 macrophages) can reduce metastasis and induce tumor regression in ectopic nude mice liver cancer models and subcutaneous HCC models (110). Human IL-15 gene-modified NK cells exhibited strong growth inhibition of transplanted human HCC tumors in xenograft nude mouse models (111). In terms of clinical trials, an early phase II study has confirmed the safety of autologous DC vaccination in patients with HCC (112). A randomized phase II study suggested that adjuvant immunotherapy with DC vaccine reduces the risk of tumor recurrence in patients with HCC who underwent standard treatment modalities other than radiofrequency ablation (113). Some ongoing clinical trials based on DCs or NK cells that have been registered are shown in Table I (https://clinicaltrials.gov/). 
So far, immunotherapy based on $\mathrm{T}$ cells, such as PD-1/PD-L1 and chimeric antigen receptor-T cell therapy have demonstrated efficacy in partial malignant tumors, such as malignant tumors of the blood system (114-116). However, the efficacy of T-cell based immunotherapy is not satisfactory in solid tumor (liver cancer), which is partly due to the suppression of T-cell responses induced by innate immune cells in the tumor microenvironment (7). With the development of precision medicine, more attention will be paid to improving immunotherapy (117). Considering the regulation of T-cell responses by innate immune cells and complex protumoral mechanisms in HCC, therapies combining innate immune cells with cytotoxic $\mathrm{T}$ cells may be a promising choice.

\section{Conclusion}

HCC remains a threat for human health due to its high degree of malignancy, poor clinical outcome and therapeutic effect (2). Increasing HCC induced by non-infectious diseases, such as NAFLD and alcoholic hepatitis occurs with the improvement of living standards and sanitary conditions (4). The occurrence and development of these HCC are associated with a chronic inflammatory microenvironment and infiltration of immune cells (109). T cells as important tumor-associated immune cells have become a hotspot of research in $\mathrm{HCC}$ (5). In fact, innate immune cells, as the other 'weapon' of defense in humans also serve important roles in the development of HCC (117). In fact, in addition to immune cells, hypoxia and glycolysis further promote the formation of the immunosuppressive tumor microenvironment and ultimately promote the metastasis and immune escape of HCC $(118,119)$. However, how these metabolic factors exactly regulate various types of immune cells and whether they are regulated by immune cells in turn remains to be explored.

With the emergence of single-cell RNA sequencing technology, people have realized the importance of the heterogeneity of innate immune cell populations in the HCC microenvironment $(120,121)$. A number of studies have indicated that the innate immune cells play opposite roles in different stages of HCC $(122,123)$. In future, studies of innate immune cells in the HCC microenvironment will become more precise and this will help in improved understanding the functions and mechanisms of immune cell subsets. In addition, the revelation of heterogeneity in the tumor microenvironment in $\mathrm{HCC}$ is helpful for overcoming the drug resistance and for designing targets for immunotherapy for HCC in the future (124).

In conclusion, both innate immune cells and $\mathrm{T}$ cells can directly mediate the development of HCC. In addition, innate immune cells can also regulate specific T-cell responses to mediate the development of HCC. This may be the key to the immune surveillance and escape in HCC. The present review will help understand the importance of innate immune cells in HCC and facilitate improved immunotherapy for patients with HCC.

\section{Acknowledgements}

Not applicable.

\section{Funding}

No funding was received.

\section{Availability of data and materials}

Data sharing is not applicable to this article, as no datasets were generated or analyzed during the current study.

\section{Authors' contributions}

GQH conceived this review, searched, analyzed and drafted the manuscript. DC and JPG participated in discussing, collecting literature and revising the manuscript for important intellectual details. XL conceived and revised the manuscript for important intellectual details. All authors read and approved the final manuscript.

\section{Ethics approval and consent to participate}

Not applicable.

\section{Patient consent for publication}

Not applicable.

\section{Competing interests}

The authors declare that they have no competing interests.

\section{References}

1. Bray F, Ferlay J, Soerjomataram I, Siegel RL, Torre LA and Jemal A: Global cancer statistics 2018: GLOBOCAN estimates of incidence and mortality worldwide for 36 cancers in 185 countries. CA Cancer J Clin 68: 394-424, 2018.

2. Villanueva A: Hepatocellular carcinoma. N Engl J Med 380: 1450-1462, 2019.

3. Kulik L and El-Serag H: Epidemiology and management of hepatocellular carcinoma. Gastroenterology 156: 477-491.e1, 2019.

4. Yang JD, Hainaut P, Gores GJ, Amadou A, Plymoth A and Roberts LR: A global view of hepatocellular carcinoma: Trends, risk, prevention and management. Nat Rev Gastroenterol Hepatol 16: 589-604, 2019.

5. Macek Jilkova Z, Aspord C and Decaens T: Predictive factors for response to PD-1/PD-L1 checkpoint inhibition in the field of hepatocellular carcinoma: Current status and challenges. Cancers (Basel) 11: 1554, 2019.

6. El-Khoueiry AB, Sangro B, Yau T, Crocenzi TS, Kudo M, Hsu C, Kim TY, Choo SP, Trojan J, Welling TH, et al: Nivolumab in patients with advanced hepatocellular carcinoma (CheckMate 040): An open-label, non-comparative, phase 1/2 dose escalation and expansion trial. Lancet 389: 2492-2502, 2017.

7. Syn NL, Teng MWL, Mok TSK and Soo RA: De-novo and acquired resistance to immune checkpoint targeting. Lancet Oncol 18: e731-e741, 2017

8. Jenne $\mathrm{CN}$ and Kubes P: Immune surveillance by the liver. Nat Immunol 14: 996-1006, 2013.

9. Ringelhan M, Pfister D, O'Connor T, Pikarsky E and Heikenwalder M: The immunology of hepatocellular carcinoma. Nat Immunol 19: 222-232, 2018.

10. Greten T, Wang X and Korangy F: Current concepts of immune based treatments for patients with HCC: From basic science to novel treatment approaches. Gut 64: 842-848, 2015.

11. Wherry EJ and Kurachi M: Molecular and cellular insights into T cell exhaustion. Nat Rev Immunol 15: 486-499, 2015.

12. Kang TW, Yevsa T, Woller N, Hoenicke L, Wuestefeld T, Dauch D, Hohmeyer A, Gereke M, Rudalska R, Potapova A, et al: Senescence surveillance of pre-malignant hepatocytes limits liver cancer development. Nature 479: 547-551, 2011.

13. Cheng JT, Deng YN, Yi HM, Wang GY, Fu BS, Chen WJ, Liu W, Tai Y, Peng YW and Zhang Q: Hepatic carcinoma-associated fibroblasts induce IDO-producing regulatory dendritic cells through IL-6-mediated STAT3 activation. Oncogenesis 5: e198, 2016. 
14. Steinman R and Cohn Z: Identification of a novel cell type in peripheral lymphoid organs of mice. I. Morphology, quantitation, tissue distribution. J Exp Med 137: 1142-1162, 1973.

15. Benites BD, Alvarez MC and Saad STO: Small particles, Big effects: The interplay between exosomes and dendritic cells in antitumor immunity and immunotherapy. Cells 8: 1648, 2019.

16. Osada T, Clay T, Hobeika A, Lyerly HK and Morse MA: NK cell activation by dendritic cell vaccine: A mechanism of action for clinical activity. Cancer Immunol Immunother 55: 1122-1131, 2006.

17. Shang N, Figini M, Shangguan J, Wang B, Sun C, Pan L, Ma Q and Zhang Z: Dendritic cells based immunotherapy. Am J Cancer Res 7: 2091-2102, 2017.

18. Chen S: Absence of CD83-positive mature and activated dendritic cells at cancer nodules from patients with hepatocellular carcinoma: Relevance to hepatocarcinogenesis. Cancer Lett 148: 49-57, 2000

19. Cai XY, Gao Q, Qiu SJ, Ye SL, Wu ZQ, Fan J and Tang ZY: Dendritic cell infiltration and prognosis of human hepatocellular carcinoma. J Cancer Res Clin Oncol 132: 293-301, 2006.

20. Shibolet O, Alper R, Zlotogarov L, Thalenfeld B, Engelhardt D, Rabbani E and Ilan Y: NKT and CD8 lymphocytes mediate suppression of hepatocellular carcinoma growth via tumor antigen-pulsed dendritic cells. Int J Cancer 106: 236-243, 2003.

21. Chen YX, Man K, Ling GS, Chen Y, Sun BS, Cheng Q, Wong OH, Lo CK, Ng IO, Chan LC, et al: A crucial role for dendritic cell (DC) IL-10 in inhibiting successful DC-based immunotherapy: Superior antitumor immunity against hepatocellular carcinoma evoked by DC devoid of IL-10. J Immunol 179: 6009-6015, 2007.

22. Tatsumi T, Takehara T, Kanto T, Miyagi T, Kuzushita N, Sugimoto Y, Jinushi M, Kasahara A, Sasaki Y, Hori M and Hayashi N: Administration of interleukin-12 enhances the therapeutic efficacy of dendritic cell-based tumor vaccines in mouse hepatocellular carcinoma. Cancer Res 61: 7563-7567, 2001.

23. Rai V, Abdo J, Alsuwaidan AN, Agrawal S, Sharma P and Agrawal DK: Cellular and molecular targets for the immunotherapy of hepatocellular carcinoma. Mol Cell Biochem 437: 13-36, 2018.

24. Santos PM, Menk AV, Shi J, Tsung A, Delgoffe GM and Butterfield LH: Tumor-derived alpha-fetoprotein suppresses fatty acid metabolism and oxidative phosphorylation in dendritic cells Cancer Immunol Res 7: 1001-1012, 2019

25. Han Y, Chen Z, Yang Y, Jiang Z, Gu Y, Liu Y, Lin C, Pan Z, Yu Y, Jiang M, et al: Human CD14+ CTLA-4+ regulatory dendritic cells suppress $\mathrm{T}$-cell response by cytotoxic T-lymphocyte antigen-4-dependent IL-10 and indoleamine-2,3-dioxygenase production in hepatocellular carcinoma. Hepatology 59: 567-579, 2014.

26. Zeng Z, Yao WJ, Xu X, Xu GQ, Long JH, Wang X, Wen ZY and Chien S: Hepatocellular carcinoma cells deteriorate the biophysical properties of dendritic cells. Cell Biochem Biophys 55: 33-43, 2009.

27. Qian BZ and Pollard JW: Macrophage diversity enhances tumor progression and metastasis. Cell 141: 39-51, 2010.

28. Vitale I, Manic G, Coussens L, Kroemer G and Galluzzi L: Macrophages and metabolism in the tumor microenvironment. Cell Metab 30: 36-50, 2019.

29. Mantovani A and Sica A: Macrophages, innate immunity and cancer: Balance, tolerance, and diversity. Curr Opin Immunol 22 231-237, 2010

30. Yeung OW, Lo CM, Ling CC, Qi X, Geng W, Li CX, Ng KT Forbes SJ, Guan XY, Poon RT, et al: Alternatively activated (M2) macrophages promote tumour growth and invasiveness in hepatocellular carcinoma. J Hepatol 62: 607-616, 2015.

31. Kang FB, Wang L, Li D, Zhang YG and Sun DX: Hepatocellular carcinomas promote tumor-associated macrophage M2-polarization via increased B7-H3 expression. Oncol Rep 33: 274-282, 2015

32. Yang Y, Ye YC, Chen Y, Zhao JL, Gao CC, Han H, Liu WC and Qin HY: Crosstalk between hepatic tumor cells and macrophages via Wnt/ $\beta$-catenin signaling promotes M2-like macrophage polarization and reinforces tumor malignant behaviors. Cell Death Dis 9: 793, 2018.

33. Yin Z, Ma T, Lin Y, Lu X, Zhang C, Chen S and Jian Z: IL-6/STAT3 pathway intermediates M1/M2 macrophage polarization during the development of hepatocellular carcinoma. J Cell Biochem 119: 9419-9432, 2018.

34. Ye Y, Xu Y, Lai Y, He W, Li Y, Wang R, Luo X, Chen R and Chen T: Long non-coding RNA cox-2 prevents immune evasion and metastasis of hepatocellular carcinoma by altering M1/M2 macrophage polarization. J Cell Biochem 119: 2951-2963, 2018.
35. Zong Z, Zou J, Mao R, Ma C, Li N, Wang J, Wang X, Zhou H, Zhang L and Shi Y: M1 macrophages induce PD-L1 expression in hepatocellular carcinoma cells through IL-1 $\beta$ signaling. Front Immunol 10: 1643, 2019.

36. Zhang J, Zhang Q, Lou Y, Fu Q, Chen Q, Wei T, Yang J, Tang J, Wang J, Chen Y, et al.: Hypoxia-inducible factor1alpha/interleukin-1beta signaling enhances hepatoma epithelial-mesenchymal transition through macrophages in a hypoxic-inflammatory microenvironment. Hepatology 67: 18721889,2018

37. Fu XT, Dai Z, Song K, Zhang ZJ, Zhou ZJ, Zhou SL, Zhao YM, Xiao YS, Sun QM, Ding ZB and Fan J: Macrophage-secreted IL-8 induces epithelial-mesenchymal transition in hepatocellular carcinoma cells by activating the JAK2/STAT3/Snail pathway. Int J Oncol 46: 587-596, 2015.

38. Capece D, Fischietti M, Verzella D, Gaggiano A, Cicciarelli G, Tessitore A, Zazzeroni F and Alesse E: The inflammatory microenvironment in hepatocellular carcinoma: A pivotal role for tumor-associated macrophages. Biomed Res Int 2013: 187204, 2013.

39. Fu XT, Song K, Zhou J, Shi YH, Liu WR, Shi GM, Gao Q, Wang XY, Ding ZB and Fan J: Tumor-associated macrophages modulate resistance to oxaliplatin via inducing autophagy in hepatocellular carcinoma. Cancer Cell Int 19: 71, 2019.

40. Tacke F: Targeting hepatic macrophages to treat liver diseases. J Hepatol 66: 1300-1312, 2017.

41. Dou L, Shi X, He X and Gao Y: Macrophage phenotype and function in liver disorder. Front Immunol 10: 3112, 2019.

42. Naugler W, Sakurai T, Kim S, Maeda S, Kim K, Elsharkawy A and Karin M: Gender disparity in liver cancer due to sex differences in MyD88-dependent IL-6 production. Science 317: 121-124, 2007.

43. Martínez-Cardona C, Lozano-Ruiz B, Bachiller V, Peiró G, Algaba-Chueca F, Gómez-Hurtado I, Such J, Zapater P, Francés R and González-Navajas J: AIM2 deficiency reduces the development of hepatocellular carcinoma in mice. Int J Cancer 143: 2997-3007, 2018.

44. Miura K, Ohnishi H, Morimoto N, Minami S, Ishioka M, Watanabe S, Tsukui M, Takaoka Y, Nomoto H, Isoda $\mathrm{N}$ and Yamamoto H: Ezetimibe suppresses development of liver tumors by inhibiting angiogenesis in mice fed a high-fat diet. Cancer Sci 110: 771-783, 2019.

45. Wu H, Zhong Z, Wang A, Yuan C, Ning K, Hu H, Wang C and Yin X: LncRNA FTX represses the progression of non-alcoholic fatty liver disease to hepatocellular carcinoma via regulating the M1/M2 polarization of Kupffer cells. Cancer Cell Int 20: 266, 2020.

46. Kuang DM, Zhao Q, Wu Y, Peng C, Wang J, Xu Z, Yin XY and Zheng L: Peritumoral neutrophils link inflammatory response to disease progression by fostering angiogenesis in hepatocellular carcinoma. J Hepatol 54: 948-955, 2011.

47. Gomez D, Farid S, Malik HZ, Young AL, Toogood GJ, Lodge JPA and Prasad KR: Preoperative neutrophil-to-lymphocyte ratio as a prognostic predictor after curative resection for hepatocellular carcinoma. World J Surg 32: 1757-1762, 2008

48. Li YW, Qiu SJ, Fan J, Zhou J, Gao Q, Xiao YS and Xu YF Intratumoral neutrophils: A poor prognostic factor for hepatocellular carcinoma following resection. J Hepatol 54: 497-505, 2011.

49. Li L, Xu L, Yan J, Zhen ZJ, Ji Y, Liu CQ, Lau WY, Zheng L and Xu J: CXCR2-CXCL1 axis is correlated with neutrophil infiltration and predicts a poor prognosis in hepatocellular carcinoma. J Exp Clin Cancer Res 34: 129, 2015.

50. Zhou SL, Dai Z, Zhou ZJ, Wang XY, Yang GH, Wang Z, Huang XW, Fan J and Zhou J: Overexpression of CXCL5 mediates neutrophil infiltration and indicates poor prognosis for hepatocellular carcinoma. Hepatology 56: 2242-2254, 2012.

51. Lu C, Rong D, Zhang B, Zheng W, Wang X, Chen Z and Tang W: Current perspectives on the immunosuppressive tumor microenvironment in hepatocellular carcinoma: Challenges and opportunities. Mol Cancer 18: 130, 2019.

52. He M, Peng A, Huang XZ, Shi DC, Wang JC, Zhao Q, Lin H, Kuang DM, Ke PF and Lao XM: Peritumoral stromal neutrophils are essential for c-Met-elicited metastasis in human hepatocellular carcinoma. Oncoimmunology 5: e1219828, 2016.

53. Wilson CL, Jurk D, Fullard N, Banks P, Page A, Luli S, Elsharkawy AM, Gieling RG, Chakraborty JB, Fox C, et al: $\mathrm{NF \kappa B} 1$ is a suppressor of neutrophil-driven hepatocellular carcinoma. Nat Commun 6: 6818, 2015

54. Jorch SK and Kubes P: An emerging role for neutrophil extracellular traps in noninfectious disease. Nat Med 23: 279-287, 2017. 
55. van der Windt DJ, Sud V, Zhang H, Varley PR, Goswami J, Yazdani HO, Tohme S, Loughran P, O'Doherty RM, Minervini MI, et al: Neutrophil extracellular traps promote inflammation and development of hepatocellular carcinoma in nonalcoholic steatohepatitis. Hepatology 68: 1347-1360, 2018.

56. Yang LY, Luo Q, Lu L, Zhu WW, Sun HT, Wei R, Lin ZF, Wang XY, Wang CQ, Lu M, et al: Increased neutrophil extracellular traps promote metastasis potential of hepatocellular carcinoma via provoking tumorous inflammatory response. J Hematol Oncol 13: 3, 2020.

57. Fulkerson P: Transcription factors in eosinophil development and as therapeutic targets. Front Med (Lausanne) 4: 115, 2017.

58. Bernsmeier C, van der Merwe S and Périanin A: Innate immune cells in cirrhosis. J Hepatol 73: 186-201, 2020.

59. Grisaru-Tal S, Itan M, Klion A and Munitz A: A new dawn for eosinophils in the tumour microenvironment. Nat Rev Cancer 10 594-607, 2020

60. Kataoka S, Konishi Y, Nishio Y, Fujikawa-Adachi K and Tominaga A: Antitumor activity of eosinophils activated by IL-5 and eotaxin against hepatocellular carcinoma. DNA Cell Biol 23 549-560, 2004.

61. Steel JL, Kim KH, Dew MA, Unruh ML, Antoni MH, Olek MC, Geller DA, Carr BI, Butterfield LH and Gamblin TC: Cancer-related symptom clusters, eosinophils, and survival in hepatobiliary cancer: An exploratory study. J Pain Symptom Manage 39: 859-871, 2010.

62. Gabrilovich D, Ostrand-Rosenberg S and Bronte V: Coordinated regulation of myeloid cells by tumours. Nat Rev Immunol 12 : 253-268, 2012

63. Arihara F, Mizukoshi E, Kitahara M, Takata Y, Arai K, Yamashita T, Nakamoto $\mathrm{Y}$ and Kaneko S: Increase in CD14+HLA-DR-/low myeloid-derived suppressor cells in hepatocellular carcinoma patients and its impact on prognosis. Cancer Immunol Immunother 62: 1421-1430, 2013.

64. Hoechst B, Voigtlaender T, Ormandy L, Gamrekelashvili J, Zhao F, Wedemeyer H, Lehner F, Manns M, Greten T and Korangy F: Myeloid derived suppressor cells inhibit natural killer cells in patients with hepatocellular carcinoma via the NKp30 receptor. Hepatology 50: 799-807, 2009.

65. Hu C, Gan J, Zhang R, Cheng Y and Huang G: Up-regulated myeloid-derived suppressor cell contributes to hepatocellular carcinoma development by impairing dendritic cell function. Scand J Gastroenterol 46: 156-164, 2011.

66. Lu L, Chang $\mathrm{C}$ and Hsu C: Targeting myeloid-derived suppressor cells in the treatment of hepatocellular carcinoma: Current state and future perspectives. J Hepatocell Carcinoma 6: 71-84, 2019

67. Chiu DK, Tse AP, Xu IM, Di Cui J, Lai RK, Li LL, Koh HY, Tsang FH, Wei LL, Wong CM, et al: Hypoxia inducible factor HIF-1 promotes myeloid-derived suppressor cells accumulation through ENTPD2/CD39L1 in hepatocellular carcinoma. Nat Commun 8: 517, 2017.

68. Li Y, Liu Z, Wang J, Yu J, Li Z, Yang H, Tang J and Chen Z: Receptor-interacting protein kinase 3 deficiency recruits myeloid-derived suppressor cells to hepatocellular carcinoma through the chemokine (C-X-C Motif) ligand 1-chemokine (C-X-C Motif) receptor 2 axis. Hepatology 70: 1564-1581, 2019

69. Xu M, Zhao Z, Song J, Lan X, Lu S, Chen M, Wang Z, Chen W, Fan $\mathrm{X}, \mathrm{Wu} \mathrm{F}$, et al: Interactions between interleukin- 6 and myeloid-derived suppressor cells drive the chemoresistant phenotype of hepatocellular cancer. Exp Cell Res 351: 142-149, 2017.

70. Sonnenberg GF and Hepworth MR: Functional interactions between innate lymphoid cells and adaptive immunity. Nat Rev Immunol 19: 599-613, 2019.

71. Warner K and Ohashi PS: ILC regulation of T cell responses in inflammatory diseases and cancer. Semin Immunol 41: 101284, 2019.

72. Han X, Huang T and Han J: Cytokines derived from innate lymphoid cells assist Helicobacter hepaticus to aggravate hepatocellular tumorigenesis in viral transgenic mice. Gut Pathog 11: 23, 2019.

73. Cai L, Zhang Z, Zhou L, Wang H, Fu J, Zhang S, Shi M, Zhang H, Yang Y, Wu $\mathrm{H}$, et al: Functional impairment in circulating and intrahepatic NK cells and relative mechanism in hepatocellular carcinoma patients. Clin Immunol 129: 428-437, 2008.

74. Wu Y, Kuang DM, Pan WD, Wan YL, Lao XM, Wang D, Li XF and Zheng L: Monocyte/macrophage-elicited natural killer cell dysfunction in hepatocellular carcinoma is mediated by CD48/2B4 interactions. Hepatology 57: 1107-1116, 2013.
75. Tatsumi $\mathrm{T}$ and Takehara $\mathrm{T}$ : Impact of natural killer cells on chronic hepatitis $\mathrm{C}$ and hepatocellular carcinoma. Hepatol Res 46: 416-422, 2016.

76. Bugide S, Green MR and Wajapeyee N: Inhibition of Enhancer of zeste homolog 2 (EZH2) induces natural killer cell-mediated eradication of hepatocellular carcinoma cells. Proc Natl Acad Sci USA 115: E3509-E3518, 2018.

77. Chen Y, Hao X, Sun R, Wei H and Tian Z: Natural killer cell-derived interferon-gamma promotes hepatocellular carcinoma through the epithelial cell adhesion molecule-epithelial-to-mesenchymal transition axis in hepatitis B virus transgenic mice. Hepatology 69: 1735-1750, 2019.

78. Luo Q, Luo W, Zhu Q, Huang H, Peng H, Liu R, Xie M, Li S, $\mathrm{Li} \mathrm{M}, \mathrm{Hu} \mathrm{X}$ and Zou Y: Tumor-derived soluble MICA obstructs the NKG2D pathway to restrain NK cytotoxicity. Aging Dis 11: $118-128,2020$

79. Vujanovic L, Stahl EC, Pardee AD, Geller DA, Tsung A, Watkins SC, Gibson GA, Storkus WJ and Butterfield LH: Tumor-derived $\alpha$-fetoprotein directly drives human natural killer-cell activation and subsequent cell death. Cancer Immunol Res 5: 493-502, 2017.

80. Mossanen J, Kohlhepp M, Wehr A, Krenkel O, Liepelt A, Roeth A, Möckel D, Heymann F, Lammers T, Gassler N, et al: CXCR6 inhibits hepatocarcinogenesis by promoting natural killer T- and CD4 T-cell-dependent control of senescence. Gastroenterology 156: 1877-1889.e4, 2019.

81. Miyagi T, Takehara T, Tatsumi T, Kanto T, Suzuki T, Jinushi M, Sugimoto Y, Sasaki Y, Hori M and Hayashi N: CD1d-mediated stimulation of natural killer $\mathrm{T}$ cells selectively activates hepatic natural killer cells to eliminate experimentally disseminated hepatoma cells in murine liver. Int J Cancer 106: 81-89, 2003.

82. Vivier E, Ugolini S, Blaise D, Chabannon C and Brossay L: Targeting natural killer cells and natural killer $\mathrm{T}$ cells in cancer. Nat Rev Immunol 12: 239-252, 2012.

83. Xiao Y, Gao Q, Xu X, Li Y, Ju M, Cai M, Dai C, Hu J, Qiu S, Zhou J and Fan J: Combination of intratumoral invariant natural killer T cells and interferon-gamma is associated with prognosis of hepatocellular carcinoma after curative resection. PLoS One 8: e70345, 2013

84. Chen J, Gingold J and Su X: Immunomodulatory TGF- $\beta$ signaling in hepatocellular carcinoma. Trends Mol Med 25: 1010-1023, 2019.

85. Li J, Lee Y, Li Y, Jiang Y, Lu H, Zang W, Zhao X, Liu L, Chen Y, Tan H, et al: Co-inhibitory molecule B7 superfamily member 1 expressed by tumor-infiltrating myeloid cells induces dysfunction of anti-tumor $\mathrm{CD}^{+} \mathrm{T}$ cells. Immunity 48: 773-786.e5, 2018.

86. Hiroishi K, Eguchi J, Baba T, Shimazaki T, Ishii S, Hiraide A, Sakaki M, Doi H, Uozumi S, Omori R, et al: Strong CD8(+) T-cell responses against tumor-associated antigens prolong the recurrence-free interval after tumor treatment in patients with hepatocellular carcinoma. J Gastroenterol 45: 451-458, 2010.

87. Zong L, Peng H, Sun C, Li F, Zheng M, Chen Y, Wei H, Sun R and Tian Z: Breakdown of adaptive immunotolerance induces hepatocellular carcinoma in HBsAg-tg mice. Nat Commun 10: 221, 2019.

88. Sachdeva M: Immunology of hepatocellular carcinoma. World J Hepatol 7: 2080-2090, 2015

89. Lu Z, Zuo B, Jing R, Gao X, Rao Q, Liu Z, Qi H, Guo H and Yin H: Dendritic cell-derived exosomes elicit tumor regression in autochthonous hepatocellular carcinoma mouse models. J Hepatol 67: 739-748, 2017.

90. Sconocchia G, Eppenberger S, Spagnoli GC, Tornillo L, Droeser R, Caratelli S, Ferrelli F, Coppola A, Arriga R, Lauro D, et al: NK cells and T cells cooperate during the clinical course of colorectal cancer. Oncoimmunology 3: e952197, 2014.

91. Li X, Yao W, Yuan Y, Chen P, Li B, Li J, Chu R, Song H, Xie D, Jiang $X$ and Wang $H$ : Targeting of tumour-infiltrating macrophages via CCL2/CCR2 signalling as a therapeutic strategy against hepatocellular carcinoma. Gut 66: 157-167, 2017.

92. Liu Y, Song Y, Lin D, Lei L, Mei Y, Jin Z, Gong H, Zhu Y, Hu B, Zhang Y, et al: NCR' group 3 innate lymphoid cells orchestrate IL-23/IL-17 axis to promote hepatocellular carcinoma development. EBioMedicine 41: 333-344, 2019.

93. Liu CQ, Xu J, Zhou ZG, Jin LL, Yu XJ, Xiao G, Lin J, Zhuang SM, Zhang YJ and Zheng L: Expression patterns of programmed death ligand 1 correlate with different microenvironments and patient prognosis in hepatocellular carcinoma. Br J Cancer 119: 80-88, 2018.

94. Lim T, Chew V, Sieow J, Goh S, Yeong J, Soon A and Ricciardi-Castagnoli P: PD-1 expression on dendritic cells suppresses CD8 T cell function and antitumor immunity. Oncoimmunology 5: e1085146, 2016. 
95. Liu J, Fan L, Yu H, Zhang J, He Y, Feng D, Wang F, Li X, Liu Q, Li Y, et al: Endoplasmic reticulum stress causes liver cancer cells to release exosomal miR-23a-3p and up-regulate programmed death ligand 1 expression in macrophages. Hepatology 70 241-258, 2019.

96. Mossanen JC, Kohlhepp M, Wehr A, Krenkel O, Liepelt A, Roeth AA, Mockel D, Heymann F, Lammers T, Gassler N, et al CXCR6 inhibits hepatocarcinogenesis by promoting natural killer T- and $\mathrm{CD}^{+} \mathrm{T}$-cell-dependent control of senescence. Gastroenterology 156: 1877-1889.e4, 2019.

97. Shigeta K, Datta M, Hato T, Kitahara S, Chen IX, Matsui A Kikuchi H, Mamessier E, Aoki S, Ramjiawan RR, et al: Dual programmed death receptor-1 and vascular endothelial growth factor receptor-2 blockade promotes vascular normalization and enhances antitumor immune responses in hepatocellular carcinoma. Hepatology 71: 1247-1261, 2020.

98. Zhou Y, Xu X, Ding J, Jing X, Wang F, Wang Y and Wang P: Dynamic changes of T-cell subsets and their relation with tumor recurrence after microwave ablation in patients with hepatocellular carcinoma. J Cancer Res Ther 14: 40-45, 2018.

99. Zhang H, Jiang Z and Zhang L: Dual effect of $\mathrm{T}$ helper cell 17 (Th17) and regulatory $\mathrm{T}$ cell (Treg) in liver pathological process: From occurrence to end stage of disease. Int Immunopharmacol 69: 50-59, 2019.

100. Kondo Y and Shimosegawa T: Significant roles of regulatory $\mathrm{T}$ cells and myeloid derived suppressor cells in hepatitis B virus persistent infection and hepatitis B virus-related HCCs. Int J Mol Sci 16: 3307-3322, 2015.

101. Wu Q, Zhou W, Yin S, Zhou Y, Chen T, Qian J, Su R, Hong L, $\mathrm{Lu} \mathrm{H}$, Zhang F, et al: Blocking triggering receptor expressed on myeloid cells-1-positive tumor-associated macrophages induced by hypoxia reverses immunosuppression and anti-programmed cell death ligand 1 resistance in liver cancer. Hepatology 70 198-214, 2019

102.Zhou SL, Zhou ZJ, Hu ZQ, Huang XW, Wang Z, Chen EB, Fan J, Cao Y, Dai Z and Zhou J: Tumor-associated neutrophils recruit macrophages and T-regulatory cells to promote progression of hepatocellular carcinoma and resistance to sorafenib. Gastroenterology 150: 1646-1658.e7, 2016.

103. Murphy K and Reiner S: The lineage decisions of helper T cells. Nat Rev Immunol 2: 933-944, 2002.

104. Geginat J, Paroni M, Maglie S, Alfen J, Kastirr I, Gruarin P, De Simone M, Pagani M and Abrignani S: Plasticity of human CD4 T cell subsets. Front Immunol 5: 630, 2014.

105. Mirchandani AS, Besnard AG, Yip E, Scott C, Bain CC Cerovic V, Salmond RJ and Liew FY: Type 2 innate lymphoid cells drive CD4+ Th2 cell responses. J Immunol 192: 2442-2448, 2014.

106. Shen G, Krienke S, Schiller P, Nießen A, Neu S, Eckstein V, Schiller M, Lorenz H-M and Tykocinski LO: Microvesicles released by apoptotic human neutrophils suppress proliferation and IL-2/IL-2 receptor expression of resting T helper cells. Eur J Immunol 47: 900-910, 2017.

107. Duffy A, Ulahannan S, Makorova-Rusher O, Rahma O, Wedemeyer H, Pratt D, Davis J, Hughes M, Heller T, ElGindi M, et al: Tremelimumab in combination with ablation in patients with advanced hepatocellular carcinoma. J Hepatol 66: 545-551, 2017

108. Lee JH, Lee JH, Lim YS, Yeon JE, Song TJ, Yu SJ, Gwak GY, Kim KM, Kim YJ, Lee JW and Yoon JH: Adjuvant immunotherapy with autologous cytokine-induced killer cells for hepatocellular carcinoma. Gastroenterology 148: 1383-1391.e6, 2015.

109. Okusaka T and Ikeda M: Immunotherapy for hepatocellular carcinoma: Current status and future perspectives. ESMO Open 3: e000455, 2018.
110. Guerra AD, Yeung OWH, Qi X, Kao WJ and Man K: The anti-tumor effects of M1 macrophage-loaded poly (ethylene glycol) and gelatin-based hydrogels on hepatocellular carcinoma. Theranostics 7: 3732-3744, 2017.

111. Jiang W, Zhang C, Tian Z and Zhang J: hIL-15 gene-modified human natural killer cells (NKL-IL15) augments the anti-human hepatocellular carcinoma effect in vivo. Immunobiology 219: $547-553,2014$

112. Palmer DH, Midgley RS, Mirza N, Torr EE, Ahmed F, Steele JC, Steven NM, Kerr DJ, Young LS and Adams DH: A phase II study of adoptive immunotherapy using dendritic cells pulsed with tumor lysate in patients with hepatocellular carcinoma. Hepatology 49: 124-132, 2009.

113. Lee JH, Tak WY, Lee Y, Heo MK, Song JS, Kim HY, Park SY, Bae SH, Lee JH, Heo J, et al: Adjuvant immunotherapy with autologous dendritic cells for hepatocellular carcinoma, randomized phase II study. Oncoimmunology 6: e1328335, 2017.

114. Sawada Y, Yoshikawa T, Shimomura M, Iwama T, Endo I and Nakatsura T: Programmed death-1 blockade enhances the antitumor effects of peptide vaccine-induced peptide-specific cytotoxic T lymphocytes. Int J Oncol 46: 28-36, 2015.

115. Gao H, Li K, Tu H, Pan X, Jiang H, Shi B, Kong J, Wang H, Yang S, Gu J and Li Z: Development of T cells redirected to glypican-3 for the treatment of hepatocellular carcinoma. Clin Cancer Res 20: 6418-6428, 2014.

116. Majzner R and Mackall C: Clinical lessons learned from the first leg of the CAR T cell journey. Nat Med 25: 1341-1355, 2019.

117. Kole C, Charalampakis N, Tsakatikas S, Vailas M, Moris D, Gkotsis E, Kykalos S, Karamouzis M and Schizas D: Immunotherapy for hepatocellular carcinoma: A 2021 update. Cancers (Basel) 12: E2859, 2020.

118. Chang C, Dinh T, Lee Y, Wang F, Sung Y, Yu P, Chiu S, Shih Y, Wu C, Huang Y, et al: Nanoparticle delivery of $\mathrm{MnO}_{2}$ and anti-angiogenic therapy to overcome hypoxia-driven tumor escape and suppress hepatocellular carcinoma. ACS Appl Mater Interfaces 12: 44407-44419, 2020

119. Tian H, Zhu X, Lv Y, Jiao Y and Wang G: Glucometabolic reprogramming in the hepatocellular carcinoma microenvironment: Cause and effect. Cancer Manag Res 12: 5957-5974, 2020.

120. Zhang Q, Lou Y, Bai X and Liang T: Intratumoral heterogeneity of hepatocellular carcinoma: From single-cell to population-based studies. World J Gastroenterol 26: 3720-3736, 2020.

121. Liu F, Qin L, Liao Z, Song J, Yuan C, Liu Y, Wang Y, Xu H, Zhang Q, Pei Y, et al: Microenvironment characterization and multi-omics signatures related to prognosis and immunotherapy response of hepatocellular carcinoma. Exp Hematol Oncol 9: 10, 2020.

122. Xiong X, Kuang H, Ansari S, Liu T, Gong J, Wang S, Zhao XY, Ji Y, Li C, Guo L, et al: Landscape of intercellular crosstalk in healthy and NASH liver revealed by single-cell secretome gene analysis. Mol Cell 75: 644-660.e5, 2019.

123. Zhang Q, He Y, Luo N, Patel SJ, Han Y, Gao R, Modak M, Carotta S, Haslinger C, Kind D, et al: Landscape and dynamics of single immune cells in hepatocellular carcinoma. Cell 179: 829-845.e20, 2019.

124. Caruso S, O'Brien D, Cleary S, Roberts L and Zucman-Rossi J: Genetics of HCC: Novel approaches to explore molecular diversity. Hepatology: May 28, 2020 (Epub ahead of print).

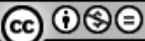

This work is licensed under a Creative Commons Attribution-NonCommercial-NoDerivatives 4.0 International (CC BY-NC-ND 4.0) License. 